This item was submitted to Loughborough's Research Repository by the author.

Items in Figshare are protected by copyright, with all rights reserved, unless otherwise indicated.

\title{
Social networks for innovation and new product development
}

PLEASE CITE THE PUBLISHED VERSION

http://dx.doi.org/10.1111/jpim.12292

\section{PUBLISHER}

() Product Development \& Management Association. Published by Wiley

\section{VERSION}

AM (Accepted Manuscript)

\section{PUBLISHER STATEMENT}

This work is made available according to the conditions of the Creative Commons Attribution-NonCommercialNoDerivatives 4.0 International (CC BY-NC-ND 4.0) licence. Full details of this licence are available at: https://creativecommons.org/licenses/by-nc-nd/4.0/

\section{LICENCE}

CC BY-NC-ND 4.0

\section{REPOSITORY RECORD}

Dolfsma, Wilfred, and Roger Leenders. 2019. "Social Networks for Innovation and New Product Development". figshare. https://hdl.handle.net/2134/20876. 


\section{Social Networks for Innovation and New Product Development - Introducing the Special Issue}

\section{Roger Leenders}

Tilburg University, Tilburg School of Social and Behavioral Sciences, r.t.a.j.leenders@tilburguniversity.edu

Wilfred Dolfsma

University of Groningen, School of Economics and Business

w.a.dolfsma@rug.nl

Roger Leenders is a professor of Networks in Organizations at the Department of Organization Studies of the University of Tilburg, the Netherlands. He holds a Ph.D. in Business Studies from the University of Groningen. He has published broadly on creativity and knowledge transfer in organizations, including in journals such as Organization Science, Journal of Applied Psychology, and the Academy of Management Journal.

Wilfred Dolfsma is Professor of Strategy and Innovation at the University of Groningen School of Economics and Business. He studied economics and philosophy, and holds a PhD in the former, from Erasmus University. He published in, a.o., the Journal of Product Innovation Management, Research Policy, Journal of Business Ethics, Journal of Evolutionary Economics, Technology Analysis and Strategic Management, the British Journal of Management, Technovation, Technological Forecasting and Social Change. He authored or edited, a.o.,Interdisciplinary Economics (ed., with S.Kesting, Routledge 2013), Government Failure (Edward Elgar 2013), and Understanding Mergers and Acquisition in the 21st Century (with K.McCarthy, Palgrave Macmillan 2012). His Institutional Economics and the Formation of Preferences (Edward Elgar 2004) won him the 2006 Gunnar Myrdal Prize.

\section{Introduction}

Innovation is, by necessity, a collaborative effort. Existing knowledge and ideas merge into new combinations, and as formerly separated knowledge come together, new knowledge emerges. There is much in the social sciences to better understand collaboration, but at the same time there is much more to explore.

The knowledge that comes together to allow for innovations to emerge, such that new product may be developed in the wake of this, is likely to be diverse in nature. Studying what happens as diverse knowledge is combined and innovations emerge can be done in largely two different manners. One is by focusing on the content of what is being combined. This approach is, perhaps, by necessity one in which qualitative analysis prevails. The extent to which the findings that result are context, or more 
specifically (knowledge) content specific can be high. Extrapolating findings to other contexts and contents can be problematic.

The other approach is to focus on the structure of the contacts between those who bring the knowledge together, who exchange knowledge. This approach in its most useful elaboration entails social network analysis. Social network analysis, as we indicate in Section 1 , suggests that the position in a networked structure of exchange goes a long way in determining how the process of exchange develops and what the outcomes of the exchange will be.

Much is already known from social network analysis about the collaboration of people, how they interact and exchange, much of that in contexts different from innovation and new product development. Some recent studies have applied the ideas and approaches from social network analysis developed for other contexts to the innovation context and have found interesting results. The innovation and new product development context, however, can be different for a number of reasons. For one, there is much more ambiguity about what is exchanged. As a result of that, either the structure of the exchange can be different, or some aspects of the exchange are highlighted more than they are in other contexts. The challenge is of course which of these results from previous studies apply when studying innovation (Borgatti and Halgin 2011). Even if the findings are specific to the innovation and new product development context, this context is important enough, for the organizations involved and for society as well, to warrant studying much more thoroughly than has hitherto been the case from this perspective. One may expect that the future will see many more studies of innovation and new product development that are emphatically inspired by but that also contribute to insights from social network analysis.

\section{Social Network Analysis}

A network is a set of actors connected by a set of ties. Social networks are social constructions arising from exchanges and joint activities among participants in a social system. These participants are often called "actors" (or "nodes" or "vertices") and can span several levels of analysis: individuals (e.g., individuals in a new product development team), teams (e.g., teams working together in a project), formal organizations (firms in a market), coalitions (e.g., lobbying alliances), or even regions and nations (e.g., members of the World Trade Organization). Actors can even include digital repositories, ideas, concepts, product modules, technical solutions, et cetera. Ties (also called "edges") connect pairs of actors and can be directed (when there is a sender and a receiver and thus a directed flow; e.g., giving advice to someone) or undirected (e.g., being co-located) and can be dichotomous (e.g., whether two firms collaborate or not) or weighted (measured on a scale; e.g., the intensity of the collaboration among two firms). Ties can vary in content, with each content essentially defining a different network (e.g., the "resource-sharing network" is distinct from the "advice network," although empirically they might be correlated). It is important to be explicit about which type of tie is studied, because a firm that has many "knowledge sharing" ties will find itself in a position that is very different from a firm with many "who sues whom" ties.

Research needs not be limited to a single substantive relation. Most network studies focus on one type of ties, usually informal ties (Reagans and McEvily 2003). Often, multiple substantive ties exist among the same set of actors, a phenomenon known as "multiplexity" (Hansen et al. 2005; Ibarra 1995). For example, a multiplex relation between two members of an innovation team exists when they have a knowledge-sharing tie and a friendship tie. Multiple networks can usually be defined among the 
same set of actors, and the extent to which the ties overlap can have an important effect on these actors (cf. Aalbers et al. 2014; Soda and Zaheer 2012). For example, team members who share knowledge and consider each other friends may be more likely to share knowledge in the future as well, compared to two team members where the friendship is lacking or conflicts may occur.

One type of tie can enhance another type of tie. For example, trust or friendship relationships may motivate knowledge sharing or the startup of a joint collaborative project. Sales persons often enhance their sales interaction with prospective customers with friendly, non-work related activities, in the hope that the friendship tie may encourage a business transaction. Research has shown that combining friendship and business in the same relationship can be beneficial, it can also create conflict (Grayson, 2007).

An important characteristic of a network tie is whether it is reciprocated or not: does a tie only go from $A$ to $B$, or is there also a tie from $B$ to $A$ ? Reciprocity is often considered a sign of relational strength: when two parties both report a tie to the other, the tie is likely to be more impactful than when only one party considers the tie to be there.

When considering a single or specific actor (and its network ties), this actor is commonly referred to as "ego" and address the actors that ego is tied to as "alters." The collection of an ego, ego's alters, and the ties among all of them is called ego's "ego-network." When studying an entire network as a whole, one often refer to the network as the "total network" or "whole network."

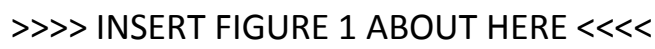

Networks can be depicted in several ways, the most common are as a network figure or as a sociomatrix. Figure 1 shows a hypothetical social network (modified from Knoke (1999)) of a NPD team and a production team. The sociomatrix (top left) is a matrix in which cell $(I, j)$ has value 1 if a tie from actor $/$ to actor $j$ exists, and 0 otherwise. A figure of the network in Figure 1 shows the nodes as circles and the directed relations as arrows with arrowheads showing the direction of the tie. When analyzing a social network, researchers often study the relational patterns that reside in them. For example, the network volume is the total number of ties among the actors in the network and the network's density is the proportion of observed ties to the number of possible connections (not counting the potential ties from actors to themselves). The network in Figure 1 has a volume of 16 (which can be seen by counting the arrowheads in the graphic or counting the 1's in the sociomatrix) and a density of $16 / 56=0.29$ (which means that almost 30 percent of all possible ties actually exist in this network). Actors typically differ in the number of ties they maintain; an actor's indegree counts the number of ties from ego's alters to ego, whereas the outdegree counts the number of ties emanating from ego to its alters. Actor $A$ has an indegree of 4 and an outdegree of 3 . A prominent term in social network analysis is centrality, a term that has immediate intuitive attractiveness, but that can be defined in a great many different ways. If would determine the shortest paths (i.e., the minimum number of steps that are needed to "walk across the network" from one actor to another) between any pair of actors, and actor's betweenness centrality is defined as the number (or proportion) of all shortest in the network that the actor is on. When considering knowledge flow networks, actors with higher betweenness centrality have an important information availability advantage over the other actors: they will likely have more timely and more complete information access than actors with lower betweenness. In addition, such high betweenness actors have the potential power to act as gatekeepers and (consciously) obstruct, mediate, or facilitate knowledge flow from one actor to another. In this example. E has the highest betweenness 
centrality, (24 out of 56), closely followed by A, whereas F, G and H aren't on a single shortest path. This means that $E$ and $A$ are at the heart of the knowledge from in this network, and that $F, G$, and $H$ are likely to receive knowledge and information the last or the least. When $\mathrm{E}$ or $\mathrm{A}$ become sick or are moved to another team, the knowledge flow among the members of these two teams will become seriously hampered, this risk is negligible when $\mathrm{H}$ or $\mathrm{B}$ leave the team.

For further detail and discussion of additional social network analysis techniques and their use, one could refer the reader to text books such as Knoke and Kuklinksi (1982), Wasserman and Faust (1994), Hanneman and Riddle (2005), Kolaczyk (2009), and Aalbers \& Dolfsma (2015).

\section{Social Networks and Innovation}

Although the imagery if the lone inventor developing new profound technology is appealing, it is an image rarely found in modern times. Innovation is a "team sport," where individuals work together in teams, team work together in projects, organizations work together in alliances, and even countries work together in international technology agendas. In fact, even the mythical lone inventor probably was not operating in splendid isolation anyway, since it is likely that much of the inventor's inspiration has come from interaction with other people or organizations, the financial resources may have been granted by bank or friends, the actual development of the product often involved the help of factories, and customers had to become involved in order to test the product for feasibility. No matter which (great) invention one would look at, it is bound to be couched in network interaction of some sort.

The many books on James Watt's contributions to the steam engine, often tell of Watt's moment of epiphany when he conceived of the idea of a condenser for Newcomen's engine. But a closer look reveals a social network surrounding the inventions of James Watt and his partner Matthew Boulton, connections between inventors, scientists and institutions (Moon, 2014). The extensive study by Moon (2014) shows how social networks connected to the work of inventors like James Watts and Leonardo da Vinci and how these networks helped shape the development of early automobiles and aviation, wireless and radio electronics, air conditioning, and clocks. Similarly, although Thomas Edison cherished his image as a lone genius, his greatest invention may have been the invention factory itself (Hargadon, 1998); in fact, Edison is now sometimes referred to as a "collective noun" rather than a single individual (Millard, 1990). The bottom line is that social networks are essential to new product development, and that the understanding of NPD can be deepened by involving social network aspects.

Social networks are inherently multilevel and can include nodes that vary from single individuals to nations and geographic regions. In this special issue, distinguishing three "levels" of analysis: networks within organizations, networks that cross the boundary of the organization, and inter-organizational networks. Networks between organizations are, to wit, maintained by individuals as well - who maintains such links, and what the nature of the links is matters greatly. Figure 2 gives a graphical representation of the multilevel character of real-life networks: members of organizations -the squares in the figure- are connected among themselves, have boundary spanning ties with their environment, and the actors in that environment are also connected. This introduction briefly discusses each level and introduce the articles that reside at each respective level.

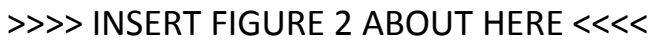

Intra-organizational networks and innovation 
NPD efforts are typically executed in a project-management approach, with the NPD team as the organizational nucleus. The innovative performance required of NPD teams is driven by the communication structure of the team (T. J. Allen, 1971, 1977; Hoegl \& Gemuenden, 2001; Katz, 1997; Leenders et al. 2007). NPD teams are information processing units; like individuals, teams process information by encoding, storing, and retrieving it (Brauner \& Scholl, 2000). Through effective communication, building on the knowledge of others, team members exchange information and create new knowledge and insight (Reagans \& Zuckerman, 2001). The team's innovative ability is greatly enhanced by appropriately coordinated communication among members of the team.

In their seminal study of how the patterns of communication among the members of R\&D projects affects the technical performance of R\&D labs, Katz and Tushman (1979) show that research projects benefit from a high degree in both the intra-project problem-solving and administrative communication networks, whereas intense interaction in the administrative communication network has a negative effect on the performance of technical service projects. For their research, Katz and Tushman ask each of 350 respondents (across 61 R\&D projects) to specify those individuals with whom the respondent had oral communication on a particular day. These sociometric-type data were collected on randomly chosen days each week for a period of fifteen weeks (Katz \& Tushman, 1979).

In a related study of how R\&D project performance is affected by the social networks of project members, Hansen (2002) collected data from a multidivisional electronics company and asked the R\&D managers in 41 divisions and the project managers of 120 projects that were executed within these 41 divisions about the inter-divisional knowledge sharing contacts within the company. Hansen asked each of the respondents to indicate which of the other 40 divisions the respondent's division had regularly sought technical and/or market-related input from, over the past two years-he followed this up by asking which of the other 40 divisions had asked the respondent's division for this type of input. Hansen was especially interested whether it mattered if the interaction maintained by a project team was with other divisions that possess related knowledge for the team's project or with other divisions that primarily worked with unrelated knowledge. Hansen's main finding was that projects in divisions with short network path lengths (ie., high closeness) to other divisions that possessed related knowledge obtained more knowledge and were completed faster. The stronger the ties to related divisions, the more ties to related divisions, and the shorter the paths to related divisions, the faster projects were completed. Ties to divisions with unrelated knowledge had no such effects.

Whereas the work above mostly focuses specifically on direct project-related communication, Allen et al. (2007) focused specifically on informal knowledge networks and found it to differ significantly from the formal structures put in place by the company to manage knowledge transfer. Studying the informal networks in the R\&D function of $\mathrm{ICl}$, a large multidivisional chemicals company, found technical personnel to engage in interaction most frequently with those in close organizational and geographical proximity to them, rather than with colleagues located in other ICI businesses or regions-formally prescribed memberships of various collaborative and knowledge-sharing structures resulted in little collaboration on problem-solving issues (2007: 193).

In this special issue, Aalbers, Dolfsma, and Leenders present a case study of five new product development projects. They focus their analysis on the ties that project teams maintain throughout the company (to other teams or to management) and then study whether these external ties support the innovative performance of the teams. Their findings suggest that the team's ability to benefit from external ties depends on the way in which the team organizes its own networking activity: although project teams that perform well tend to have more external ties in general and ties to management in 
particular. However, they find that these ties should be concentrated in the hands of a few team members only, so that the external networking activity becomes a specific task for some team members, but not for others.

\section{Innovation networks crossing organizational boundaries}

Just like the lone inventor has become an image of the past, innovating organizations rarely go at it alone either. Organizations involve a large variety of partners in their NPD process - such as users, customers, suppliers, distributors, intermediaries, and even competitors-and engage in a varied set of collaborative arrangements-such as alliances, joint ventures, collective research, co-development, informal networking, competitions, co-opetition, et cetera. As a result, companies increasingly shift from innovation activities that are centered on internal resources ("firm-centric innovation") to those that are centered on external networks ("network-centric innovation") (Nambisan \& Sawhney, 2011). From the viewpoint of the organization, these collaborations form an ego-network with the organization as the ego. There is ample evidence that ego-networks can have a profound effect on a firm's innovative performance. For example, in a longitudinal study of 77 telecommunications equipment manufacturers, Phelps (2010) found that technological diversity in a firm's NPD alliance network positively impacts the firm's exploratory innovation. In addition, the higher the density of the network among the firm's partners (i.e., the higher the extent to which the firm's partners are also alliance partners among themselves), the stronger this effect of diversity; this moderation effect is likely to occur due to the increased trust, joint problem-solving efforts, and improving knowledge detection and transfer from and between the firm's diverse partners that is associated with high density innovation alliances networks.

Whereas there is ample research on the interplay of innovation and inter-firm networks and also quite a bit of research on intra-organizational innovation networks, research that explicitly focuses on network ties that connect the inside of the organization with its outside (e.g., ties between internal NPD teams and external potential customers) is quite scant. This is surprising, because successful innovation often requires firms to get knowledge, ideas, financial and other resources from "the outside" and bring them into the firm, where they need to be routed to the right place at the right time. In other words, successful innovation requires firms to maintain both effective arrangement of external ties and a smooth internal network that allows the firm to integrate the externally acquired knowledge into its own process and that feeds the external ties with input from the firm itself. From this point of view, part of the literature considers firms as "knowledge brokers": firms seeking strategic advantage by gaining access to a variety of industries, exploiting their network ties to learn about a wide range of existing problems and solutions, creating innovative solutions in the form of new combinations of these existing ideas (Hargadon, 1998)-firms such as IDEO, Hewlett-Packard, Boeing, and McKinsey.

Some firms are markedly better at building, maintaining, and exploiting effective networks. Sivadas \& Dwyer (2000) argued that some firms are simply more competent at cooperation than are others and that this "cooperative competency" explains new product success. Ritter and Gemünden (2003) studied a sample of 308 German mechanical and electrical engineering companies, focusing on their network competence. They found the competence of a firm to manage its technological network allows it to intensively involve others in their technological development process. In addition, network competence was also found to be positively related to the firm's innovation success, above and beyond their own internal technological competencies. In fact, Gulati et al. (2000) pointed out that the structural pattern of a firm's relationships can be an inimitable resource; in order to exploit the potential for innovative competitive advantage embodied in their network ties, lead firms should manage the structure of their networks carefully. In a longitudinal study of 49 firms who were competing to set two technology 
standards, Soh (2010) demonstrated that, during the race to define a dominant design, firms that networked cleverly were able to force their preferred dominant design over that preferred by competitors. He showed that firms benefit from positioning themselves more centrally than others in alliance networks, this helps them attract suppliers of complementary products and turn market resources away from competing standards. High network centrality is beneficial when participating firms within the same technological community have a strategic intent to acquire and share knowledge broadly and common standardization goals are widely acknowledged and promoted. The clever networking of such firms should increase the incentive of potential suppliers and buyers to invest in their standard (Soh, 2010).

In this special issue, the paper by Lynch, O'Toole \& Biemans as well as the paper by Schleimer \& Faems deal with social networks at the intersection of the firm and its external environment. Schleimer \& Faems focus on the impact that intra-firm networks have on the success of collaborative endeavors the firm engages in. Their findings suggest that both intra-firm and inter-firm collaboration increase NPD performance, but that this mainly occurs in case of incremental innovation. When the NPD project is aimed at radical innovation, a trade-off between intra- and inter-firm collaboration kicks in, effectively canceling their joint positive effect. Overall, the paper suggests trade-offs between inter-firm and intrafirm knowledge flows, which might have implications for the way firms manage their collaborative (radical) NPD activity.

The contribution by Lynch, O'Toole \& Biemans focuses specifically on the collaboration between firms and their customers. Although there is ample literature on the involvement of customers in a firm's NPD activity, the actual ego-network that results from such involvement has rarely been studied systematically. The authors propose a series of metrics that capture important characteristics of this network. The metrics address the antecedents of the ego-network (e.g., the firm wanting the customers to contribute to idea screening or product testing), the structure of the ensuing network (e.g., range, tie longevity), and the way in which interactions occur (e.g., frequency and intensity of the interaction and the organizational level at which the interaction takes place). The proposed metrics can guide future research on firm-customer interaction to focus on a specific set of variables that distinguish one customer network from another and that can help explain how and why one firm can employ its customers more effectively in NPD than can others.

\section{Inter-organizational networks and innovation}

There is an abundance of network studies at the inter-firm or industry level (Zaheer et al. 2010). Network ties among firms have been argued to stimulate trust, knowledge flow, flow of ideas, and innovative culture (Phelps 2010). Sometimes organizational networks are located in specific regions, such as Silicon Valley (California), Bangalore (India), Digital Media City (Seoul, South Korea), Eindhoven (The Netherlands), or Tel Aviv (Israel) with the highest density of tech startups in the world. What makes such regions work is the network activity among the firms, without their interconnecting it would be unlikely for such regions to be (and remain) truly innovation hotbeds (Ozcan and Eisenhardt 2009).

The prevailing finding is that inter-firm networks are conducive to innovation, because it gives firms access to diverse knowledge and helps them, jointly, combine complementary resources (Dyer \& Singh, 1998; Gulati \& Gargiulo, 1999; Ingram and Roberts 2000; Phelps, Heidl, \& Wadhwa, 2012; Reagans and Zuckerman 2001; Soh, 2003) 
Rampersad, Quester and Troshani (2010) investigated how inter-firm innovation networks can be managed and how their outcomes affected. Drawing on data from Australian high technology networks in information and communications technology and biotechnology/nanotechnology, they found evidence for the impact of power distribution, trust, coordination, and harmony on achieving network outcomes. However, the specific relationships among several of their variables varied per industry, suggesting that much is still unknown about the functioning of alliance networks as a whole.

Besides long-lived alliance networks that exist for innovative purposes, but not necessarily for a specific innovation, many inter-organizational networks are setup specifically to produce a single innovation (or a set of related innovations). Here, organizations come together in a project-like manner, with (largely) predetermined outcomes in mind and clear joint goals. Kratzer and colleagues (2007) describe the case of a world-leading diaper manufacturer that established an innovation network that included itself and its suppliers, customers, and logistics partners, with the intention to develop innovations that would benefit the entire chain.

In an in-depth study of the functioning of an international innovation network within the space industry, Schönrok (2010) investigated how communication and knowledge-sharing ties emerged and vanished among the partners. Task-interdependence (when coupled with proficient task decomposition) strongly guided knowledge-sharing and coordination communication. One interesting finding in her study is that the factors that are often reported to govern intra-organizational communication and knowledgesharing do not necessarily carry over to the project/inter-organizational network level. This suggests that research at both levels of analysis is needed (and research that crosses these levels).

In this issue, Gilsing, Cloodt, and Roijakkers investigate the evolution of a technology-based inter-firm alliance network in the biopharmaceutical industry over about 25 years. Focusing on two ways in which the embeddedness of a firm in a network a firm can be understood (i.e., "structural", relating to the extent that a firm can gain access to resources owned by organizations it is not directly connected to, and "positional," referring to the benefits a firm accesses through its specific network position-such as being more or less central). A main finding is that the progression of network embeddedness is not linear throughout all industry development stages, which implies that the value of a network neither remains constant over time, nor does it change linearly. This not only generates nuance vis-à-vis prevailing theory, it also suggests that managers may need to think differently about their firm's network activity, than has been suggested so far in the literature.

\section{Networks and Innovation in Markets}

At the highest level of aggregation, one would consider networks that live beyond innovating organizations per se. Usually, these are networks of individuals, ranging from inventor networks to networks of customers or users. With the strengthening of the open source model, many user networks have become powerful innovators. The connections between them, and the shape of a network that results, can significantly influence the innovative outcome but this has largely remained unexplored (cf. West \& Bogers 2013). Some of these networks are created fully by users themselves, such as the networks that develop(-ed) Linux, Wikipedia, Rodeo kayaking, or the statistical software R. Others are instigated by companies that hope to draw ideas and inspiration from them-examples include LEGO, Akzo Nobel, Unilever, and Beiersdorf Pearlfinder. Ways in which such networks are "organized" include, among others, (the somewhat overlapping forms of) webforums, competitions, crowdsourcing, or open innovation. Here, this introduction is particularly interested in the networks that are built by and maintained by individuals. 
User innovation networks bring a great advantage to users over the manufacturer-centric innovation in that they enable each user to develop exactly what it wants rather than being restricted to available marketplace choices or relying on a specific manufacturer to act as its (often very imperfect) agent. Moreover, individual users do not have to develop everything they need on their own: they can benefit from innovations developed by others and freely shared within and beyond the user network (Hippel, 2007: 294).

There are several examples of such networks in this special issue. Kratzer, Lettl, Franke, and Gloor study the network of users and investigate whether lead users-innovative users of a product or service who have needs that are not included in the product and who would benefit greatly if they obtain a solution to these needs (Hippel, 1986)-occupy different positions in their social network than do non-lead users. Because lead users not only are innovative, but develop solutions to real needs that other customers of the company (whose products are innovated by the lead user) could benefit from as well, companies are often interested in tracing who its lead users are. Identifying its lead users can be costly and time-consuming, so firms could benefit greatly from being able to recognize its lead users from the position they occupy in easily accessible and measurable social networks. Kratzer and his colleagues find that lead users to appear to occupy a distinct network position and that certain web mining techniques may be useful in a firm's quest for its lead users.

A slightly different, contemplative, perspective is provided by lacobucci and Hoeffler who, both coming from the field of marketing, explore how firms can tap into the social networks around them and leverage their ability to develop radically new products. Rather than identifying lead users from the online networks they inhabit, lacobucci and Hoeffler discuss the option of mining the online conversations that occur among lead users in order to uncover common problems, novel solutions, or analogous challenges. Furthermore, they discuss that the way in which new products and ideas diffuse through the market isn't quite understood yet, despite the existence of well-researched and oft-cited models. The reason for the lack of insights these models have generated -they focus specifically on the Bass model (Bass, 1969) - is because they are underdeveloped in terms of the network theory that underlies them. Extending the model with established findings from the social networks literature on how behavior, such as product adoption, is mimicked among customers might further improve the model, which is especially useful in cases when no previous adoption history is available by which to calibrate the "regular" parameters of the Bass model. In addition, the authors argue that firms could gain much additional relevant knowledge and ideas by following, establishing, supporting, and participating in online platforms that stimulate focused networking among dedicated (potential) customers and users.

In their contribution to this special issue, Mukherjee, Uzzi, Jones, and Stringer employ a network approach to study innovation by individuals, in particular by scientists. Their starting point is that the products that scientists develop are papers in academic journals, in which their created knowledge and ideas are expressed. Mukherjee et al. address two issues: how can one objectively measure how innovative a new product (i.e., a paper) is, and what makes an innovative product successful? Their approach is not to study the network among the innovators (i.e., the scientists) themselves, but to study the network 'inside' their products. Specifically, they argue that new products (such as articles) are made up of combinations of already existing products and technologies (as evident from citations), mixed with a bit of newness. The way in which existing technology is combined in a new product can itself be more or less new: combinations of technologies have already been combined in many previous products can be characterized as conventional, whereas combining existing technologies that have not been combined much before is a sign of novelty. The authors thus build a network of citations between 
scientific articles (and the journals these have been published in) and compare the dyads of journals that are jointly referenced by an individual paper to the general tendency for this dyad to occur across the population. In line with the product innovation literature (Glynn, Kazanjian, \& Drazin, 2010; Griffin, 1997; Griffin \& Page, 1996; Van Engelen, Kiewiet, \& Terlouw, 2001) and innovation in science (Guimerà, Uzzi, Spiro, \& Amaral, 2005; Wuchty, Jones, \& Uzzi, 2007)), the authors find that teams are better at reaching for novel combinations than are individuals and that the output by teams is more likely to be successful than that by individuals. A surprising finding is that their extensive analysis shows that science appears to become increasingly conventional and that drawing on atypical combinations of prior work becomes increasingly rare. Considering that science is an important indicator of the (fundamental) research that is done in universities and company laboratories, this is an alarming finding that, it is suggested, should be researched in more depth in future research.

\section{Conclusion}

Although innovation is a collaborative endeavor, where multiple actors interact and work together to develop something new. Surprisingly, there is relatively little research that studies the patterns and structures of the collaboration ties with the help of formal theory and methods specifically developed to do this. Social network analysis is a method that explicitly addresses interaction patterns. The eight papers in this special issue (and the references therein), provide a the reader with an overview of the type of research that can fruitfully be done when a social network lens is employed, Some of the papers employ specific social network analysis measures, others address the role of social networks more loosely, but each highlights unique aspects of how a social network study of innovation offers novel insights. It is the expectation in this introduction that the reader will enjoy the special issue as much as we have enjoyed bringing the papers together. But above all, many more scholars may find inspiration in the approach and will put on a social network lens as part of their future work on innovation.

\section{REFERENCES}

Aalbers, R., and W. Dolfsma. 2015. Innovation networks - managing the networked organization. London \& New York: Routledge.

Aalbers, R., W. Dolfsma, and O. Koppius. 2014. Rich ties and innovative knowledge transfer within a firm. British Journal of Management 25(4): 833-848.

Allen, J., A. D. James, and P. Gamlen. 2007. Formal versus informal knowledge networks in R\&D: A case study using social network analysis. R\&D Management 37(3): 179-196.

Allen, T. J. 1971. Communication networks in R\&D labs. R\&D Management 1(1): 14-21.

Allen, T. J. 1977. Managing the flow of technology. Boston: MIT Press.

Bass, F. M. 1969. A new product growth model for consumer durables. Management Science 15(5): 215227. 
Borgatti, S. P., and D. S. Halgin. 2011. On network theory. Organization Science 22(5): 1168-1181.

Brauner, E., and W. Scholl. 2000. The information processing approach as a perspective for group research. Group Processes and Intergroup Relations 3(2): 115-122.

Dyer, J. H., and H. Singh. 1998. The relational view: Cooperative strategy and sources of interorganizational competitive advantage. Academy of Management Review 23(4): 660-679.

Glynn, M. A., R. Kazanjian, and R. Drazin. 2010. Fostering innovation in complex product development settings: The role of team member identity and interteam interdependence. Journal of Product Innovation Management 27(7): 1082-1095.

Grayson, K. 2007. Friendship versus business in marketing relationships. Journal of Marketing 71(4): 121139.

Griffin, A. 1997. PDMA research on new product development practices: Updating trends and benchmarking best practices. Journal of Product Innovation Management 14(6): 429-458.

Griffin, A., and A. L. Page. 1996. PDMA success measurement project: Recommended measures for product development success and failure. Journal of Product Innovation Management 13(6): 478-496.

Guimerà, R., B. Uzzi, J. Spiro, and L. A. N. Amaral. 2005. Team assembly mechanisms determine collaboration network structure and team performance. Science 308(5722): 697-702.

Gulati, R., and M. Gargiulo. 1999. Where do interorganizational networks come from? American Journal of Sociology 104(5): $1398-1438$.

Gulati, R., N. Nohria, and A. Zaheer. 2000. Strategic networks. Strategic Management Journal 21(3): 203215.

Hanneman, R. A., and M. Riddle. 2005. Introduction to social network methods. Retrieved from: http://www.faculty.ucr.edu/ hanneman/nettext/

Hansen, M. T. 2002. Knowledge networks: Explaining effective knowledge sharing in multiunit companies. Organization Science 13(3): 232-248.

Hansen, M. T., M. L. Mors, and B. Løvås. 2005. Knowledge sharing in organizations: Multiple networks, multiple phases. Academy of Management Journal 48(5): 776-793.

Hargadon, A. 1998. Firms as knowledge brokers: Lessons in pursuing continuous innovation. California Management Review 40(3): 209-227.

Hippel, E. V. 1986. Lead users: A source of novel product concepts. Management Science 32(7): 791-805.

Hippel, E. V. 2007. Horizontal innovation networks - by and for users. Industrial and Corporate Change 16(2): 293-315. 
Hoegl, M., and H. G. Gemünden. 2001. Teamwork quality and the success of innovative projects: A theoretical concept and empirical evidence. Organization Science 12(4): 435-449.

Ibarra, H. 1995. Race, opportunity, and diversity of social circles in managerial networks. Academy of Management Journal 38(3): 673-703.

Ingram, P., and P. Roberts. 2000. Friendship among competitors in the Sydney hotel industry. American Journal of Sociology 106(2): 387-423.

Katz, R. 1997. Managing creative performance in R\&D teams. In The human side of managing technological innovation, ed. R. Katz, 177-186. New York: Oxford University Press.

Katz, R., and M. Tushman. 1979. Communication patterns, project performance, and task characteristics: An empirical evaluation and integration in an R\&D setting. Organizational Behavior and Human Performance 23(2): 139-162.

Knoke, D. 1999. Organizational networks and corporate social capital. In Corporate social capital and liability, ed. R. T. A. J. Leenders and S. M. Gabbay, 17-42. Norwell: Wolters-Kluwer Academic Publishers.

Knoke, D., and J. H. Kuklinski. 1982. Network analysis. Beverly Hills: Sage.

Kolaczyk, E. D. 2009. Statistical analysis of network data: Methods and models. New York: Springer.

Kratzer, J. K., R. T. A. J. Leenders, J. M. L. Van Engelen, and L. Kunst. 2007. InnovationNet: The art of creating and benefiting from innovation networks. Assen: Van Gorcum.

Leenders, R. T. A. J., J. M. L. Van Engelen, and J. Kratzer. 2007. Systematic design methods and the creative performance of new product teams: Do they contradict of complement each other? Journal of Product Innovation Management 24(2): 166-179.

Millard, A. 1990. Edison and the business of invention. Baltimore, MD: Johns Hopkins University Press.

Moon, F. M. 2014. Social networks in the history of innovation and invention. New York: Springer.

Nambisan, S., and M. Sawhney. 2011. Orchestration processes in network-centric innovation: Evidence from the field. Academy of Management Perspectives 25(3): 40-57.

Ozcan, P., and K.M. Eisenhardt. 2009. Origin of alliance portfolios: Entrepreneurs, network strategies and firm performance. Academy of Management Journal 52(2): 246 -279.

Phelps, C. C. 2010. A longitudinal study of the influence of alliance network structure and composition on firm exploratory innovation. Academy of Management Journal 53(4): 890-913.

Phelps, C. C., R. Heidl, and A. Wadhwa. 2012. Knowledge, networks, and knowledge networks: A review and research agenda. Journal of Management 38(4): 1115-1166. 
Rampersad, G., P. Quester, and I. Troshani. 2010. Managing innovation networks: Exploratory evidence from ICT, biotechnology and nanotechnology networks. Industrial Marketing Management 39(5): 793805.

Reagans, R., and E. W. Zuckerman. 2001. Networks, diversity, and productivity: The social capital of corporate R\&D teams. Organization Science 12(4): 502-517.

Reagans, R., and B. McEvily. 2003. Network structure and knowledge transfer: The effects of cohesion and range. Administrative Science Quarterly 48(2): 240-267.

Ritter, T., and H. G. Gemünden. 2003. Network competence: Its impact on innovation success and its antecedents. Journal of Business Research 56(9): 745-755.

Schönrok, J. E. 2010. Innovation at large: Managing multi-organization, multi-team projects (Vol. 20). Peter Lang.

Sivadas, E., and F. R. Dwyer. 2000. An examination of organizational factors influencing new product success in internal and alliance-based processes. Journal of Marketing 64(1): 31-49.

Soda, G., and A. Zaheer. 2012. A network perspective on organizational architecture: Performance effects of the interplay of forma land informal organization. Strategic Management Journal 33(6): 751771.

Soh, P.-H. 2003. The role of networking alliances in information acquisition and its implications for new product performance. Journal of Business Venturing 18(6): 727-744.

Soh, P.-H. 2010. Network patterns and competitive advantage before the emergence of a dominant design. Strategic Management Journal 31(4): 438-461.

Van Engelen, J. M. L., D. J. Kiewiet, and P. Terlouw. 2001. Improving performance of product development teams through managing polarity. International Studies of Management and Organization 31(1): 46-63.

Wasserman, S., and K. Faust. 1994. Social network analysis: Methods and applications. New York: Cambridge University Press.

West, J., and M. Bogers. 2013. Leveraging external sources of innovation: A review of research on open innovation. Journal of Product Innovation Management 31(4): 814 -831.

Wuchty, S., B. F. Jones, and B. Uzzi. 2007. The increasing dominance of teams in production of knowledge. Science 316(5827): 1036-1039.

Zaheer, A., R. Gözübüyük, and H. Milanov. 2010. It's the connections: The network perspective in interorganizational research. Academy of Management Perspective 24(1): 62-77. 
Figure 1: Hypothetical knowledge and information sharing network
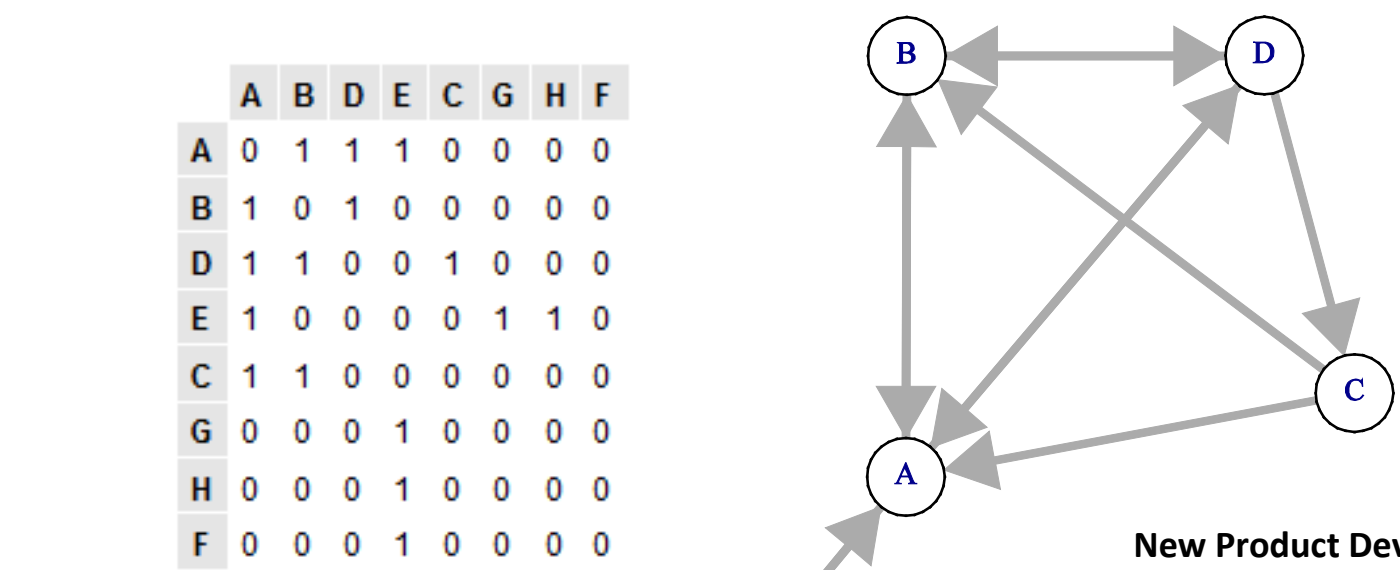

New Product Development Team

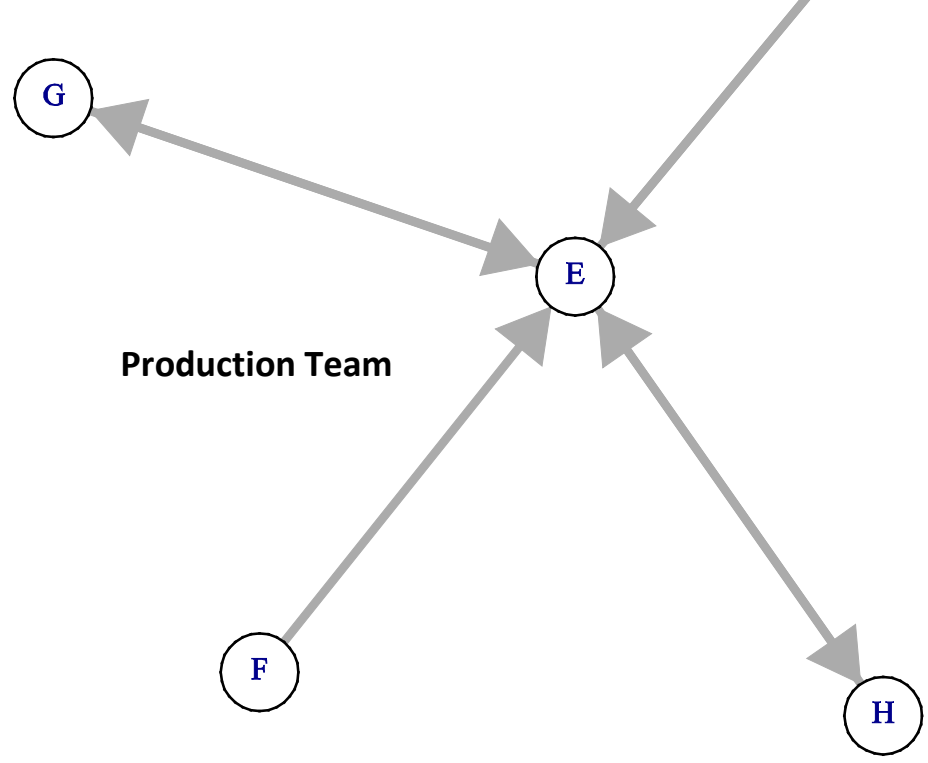


Figure 2: Networks within, between, and around organizations

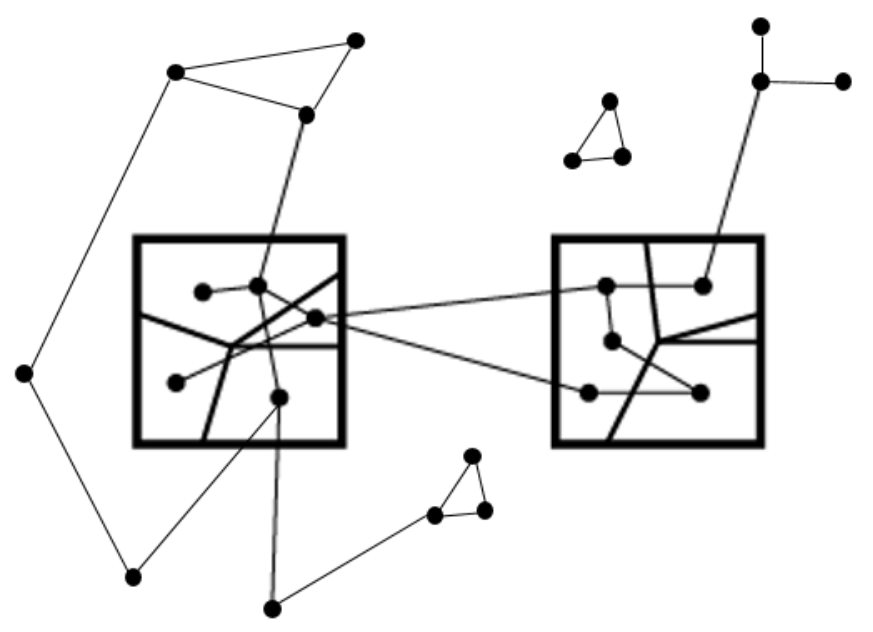

